\title{
Opening Black-Box of Teaching-Practice: Pre-service Teachers' Learning from the Hidden Curriculum Perspective
}

\author{
Lili Hurioğlu1, Learning Systems Institute, Florida State University, Tallahassee, USA, Ihurioglu@fsu.edu, \\ ORCID: 0000-0002-4938-1815 \\ *Akın Efendioğlu, Elementary School Teaching, Cukurova University, Turkey, eakin@cu.edu.tr, \\ ORCID: 0000-0001-6756-7405
}

\begin{abstract}
The main purpose of the study is to reveal the hidden learning-outcomes gained through teaching practice of pre-service teachers regarding hidden curriculum (HC) perspective. After a nineweek teaching practice course, the pre-service teachers $(n=11)$ attended to a single case study. An interview related to their in-class learning experiences was implemented. Finally, based on the HC, a deductive content analysis was conducted. Results indicated that totally 11 learning themes were determined. Even though themes have a complex structure on their own, they explicitly show that hidden learning outcomes reflect three basic learning domains as "learning to learn (LL)", "learning the profession (LP)" and "learning to be an expert (LBE)". As a conclusion, the results have been discussed in terms of HC, teachers' professional development, the teaching profession, metacognition, and official teacher training curriculum (OTTC) perspectives.
\end{abstract}

Keywords: Pre-service teachers; teaching practice course; hidden curriculum; hidden learning outcomes; teaching profession

Received: 16.12 .2019

Accepted: 29.06 .2020

Published: 01.01 .2021

\section{INTRODUCTION}

\section{Research Problem}

Before teachers begin teaching profession during their pre-service training process, they must acquire very important qualifications and skills to be a qualified teacher. In many developed and developing countries, the official teacher training curriculum (OTTC) have been implemented in order to support pre-service teachers' quality and professional development. Within the OTTC, one of the most important implementations, which was defined as a heart of teacher education by Senemoğlu (1993), is the teaching practice which mainly focuses on students' acquisition of the qualifications required by teaching profession. Darling-Hammond and Post (2000) and Peske and Haycock (2006) state that in relation to teachers' quality (high or low), achievement of the students increases or decreases. However, learning-outcomes gained through the teaching practice include both OTTC and hidden curriculum (HC). It would be better to explain HC as this term explicitly includes everything that is learnt beyond what is considered the OTTC result (Bergenhenegouwen, 1987). Moreover, it is seen that the HC shows the unwritten learningoutcomes which are necessary for successful completion of OTTC (Konieczka, 2013). Although the HC has vital importance for teachers' professional development, unfortunately, receives very little attention (Horn, 2003). But, based on teaching practice, determining significant learningoutcomes occurred in the HC also important in order to present useful information for the improvement of OTTC (Maulana, Helms-Lorenz \& van de Grift, 2015).

On the other hand, aims of OTTC is known clearly, yet there is not adequate information as to what the pre-service teachers gain through the teaching practice regarding HC (Biermann,

\footnotetext{
*Corresponding Author: eakin@cu.edu.tr

${ }^{1} \mathrm{Dr}$. Hurioğlu is continuing work as an assistant professor in the Department of Educational Sciences at İstanbul University-Cerrahpaşa, Turkey, meanwhile, she is a postdoctoral researcher at Learning Systems Institute, FSU, USA.
} 
Karbach, Spinath \& Brunken, 2015). Langhout and Mitchell (2008) focused on the question that "how does the hidden curriculum challenge the teacher's vision of creating an academically engaging learning environment for all students?"(p.594). In addition, Nguyen (2009) states that teachers' socialization influences their teaching process based on their own experience gained through learners within a learning-teaching environment. Although there are several research projects conducted by understanding the students' life at school regarding their learning derived from the hidden curriculum, little has known related to learning, during the pre-service teachers' teaching practice process within the same domain. From these points of views, the main purpose of the study is to reveal the learning-outcomes gained through the teaching practice of pre-service teachers regarding HC perspective. Therefore, the following research question has been addressed: What are the hidden learning themes of pre-service teachers within the process of their teaching practice?

\section{Conceptual Background}

Learning needs of pre-service teachers within the teaching practice process. Increasing the quality of teaching is possible to support the quality of the teacher training process. Teaching practice course has been in the center (heart) of the OTTC in order to develop pre-service teachers' such teaching skills as implementing instruction, preparing lesson plans, overcome classroom management, communicative aspects, teaching-learning methods-techniques (Gebhard, 2009; Fan Tang, 2004; Senemoğlu, 1993). In Turkey, the framework and the goals of teaching practice course have been presented by Ministry of National Education. Then, the objectives have been determined by the education faculty and the department regarding the framework and the goals. Within the context of OTTC, the objectives of teaching practice course are presented in Table A (see Appendix). Moreover, according to Fang (1996), in teaching practice, pre-service teachers take an expedition towards teaching with the aim of learning the students' characteristics, classroom activities and problems as well as learning how to overcome these realities which they will be quite likely to encounter in the future (Fang, 1996; Grudnoff, 2011). As stated by Yuan and Lee (2014), in teaching practice process, pre-service teachers interrogate and reflect their beliefs and values and these reflections can support pre-service teachers' learning and professional development; in that, teacher belief is defined as 'pre- or inservice teachers' implicit assumptions about students, learning, classroom, and the subject matter to be taught' (Kagan, 1992, p. 66) and also the belief is resistance to change (Murphy, Delli, \& Edwards, 2004; Ng, Nicholas, \& Williams, 2010). Based on Kagan's definition, it can be claimed that teacher belief has quite likely to have a positive effect on pre-service teachers' learning and classroom activities (Tang, Lee \& Chun, 2012). When pre-service teachers start teaching practice process, as a part of their beliefs development process "Awareness: Awareness of a discrepancy, conflict or coherence' and 'Disagreement: Rejection of existing beliefs or presented information" constructs come into prominence (Cabaroglu \& Roberts, 2000, p.393).

On the other hand, one of the most important aims of teaching practice is gaining preservice teachers teaching experience and classroom management skills. In this respect, a study conducted by Muallana et al. (2013) and Muallana et al. (2015) allege that teachers' teaching quality increases school year period. Moreover, at the earlier stages of teaching profession teachers are tend to face difficulties in providing:

- "a supportive learning climate,

- managing the classroom effectively,

- displaying clear instruction,

- activating students' learning,

- attending to differences between students' needs,

- teaching students how to learn effectively" (Maulana, Helms-Lorenz \& van de Grift, 2015, p.225).

Based on the difficulties given above, HC may provide opportunities for teachers to overcome these difficulties. In that, a big part of $\mathrm{HC}$ arises from the school and classroom climate, students' characteristics, cultural and moral values (Horn, 2003), communication styles of 
teacher and students, and social characteristics and culture of a society (Zorec \& Došler, 2016). In this respect, during the teaching practice, teachers have experiences and can learn some suitable information which they may use to overcome these difficulties.

\section{Hidden Curriculum}

Defining the hidden curriculum (HC) as a concept is very hard since it has been influenced by several constructs of school life; besides, it is called the unwritten curriculum or sometimes implicit education within the literature. Therefore, instead of defining the $\mathrm{HC}$ as a concept, determining its framework will be more informative. HC includes students' all learning in the school except that learnings are derived from the planned and intended curriculum. In another view, Sambell and McDowel (1998) state that hidden curriculum "an opposite metaphor to describe the shadowy, ill-defined and amorphous nature of that which is implicit and embedded in educational experiences in contrast with the formal statements about curricula and the surface features of educational interaction" (pp.391-392). This framework shows a picture related to the characteristics of the HC. In that, HC is influenced by administrators', teachers', and students' beliefs, behaviors, as well as personality (Condon et al. 2014; Garrett, 2010; Zorec \& Došler, 2016), along with cultural values (Garrett, 2010; Konieczka, 2013; Margolis et al. 2001; Winter \& Cotton, 2012), rules and structures of a school and a classroom (Dutton, 1987; Hafferty \& O'Donnell, 2014), school and classroom climate (Dutton, 1987), pattern of communication and media (Horn Jr, 2003), characteristics of the social environment where the school is located. In other words, learning in the $\mathrm{HC}$ framework is not directly intended behaviors (cognitive, affective, or psychomotor), they can be thought as learning derived from the hidden messages (Lynch 1989; Sarl, 2007), attitudes, values, beliefs, and behaviors (Konieczka, 2013; Skelton, 1997; Langhout \& Mitchell, 2008; Winter \& Cotton, 2012). For instance; students wait quietly for their teachers, cooperate with their teachers and peers, being tidy and punctual, trying to solve the problem fearlessly. Above mentioned remarks are learning outcomes within the scope of the hidden curriculum. Those outcomes are not individual goals get by students but internalized by many of the students consistently. All learning being as features of school life and requirements for conformity to institutional expectations had little to do with educational goals but were essential for satisfactory progression through school (Margolis et al. 2001, p.5). Moreover, such learning is very important to support students' learning within the scope of the official curriculum such as academic achievement and failure which is closely related to mastery of the hidden curriculum (Jackson, 1968, p.34). From this point of view, one of the reasonable inferences is that teachers are exposed to different experiences both in- and -out of the classroom so that they can learn along similar channels like their students. According to Ahola (2000), the hidden curriculum has some basic domains such as (1) "learning to learn", (2) "learning the profession", and (3) "learning to be an expert" (Anderson, 2001, p.30). It is clear that these domains have vital connections with pre-service teachers' learnings which have an effect on their behaviours and profession. Therefore, based on the hidden curriculum, learning of the pre-service teachers within their teaching practice may give an opportunity to support their professional development and social functions of OTTC.

\section{METHOD}

In this single case study, a qualitative research approach was used. Despite the fact that there was a common belief about the weakness of single case study as a research method, Orum, Feagin, and Sjoberg (1991) state that the study of the single case or an array of several cases remains indispensable to the progress of the social sciences (p.1). According to Flyvbjerg (2006), there are claims advocating that a single-case studies are considered to be devastating to the case as a scientific method, yet it is not a correct way to reach a conclusion that one cannot generalize from a single case and it should be overrated as the main source of scientific progress. Moreover, since the natural structure of the hidden curriculum and learning, the main variable of the study, does not allow varying data sources as the pre-service teachers' learning in the hidden 
curriculum, it cannot be observed directly or inferred from their behavioral patterns. The preservice teachers $(n=11)$ attended the teaching practice course for nine weeks. At the end of the ninth week, an interview related to their in-class learning-teaching experiences was implemented. Finally, based on the hidden curriculum perspective, the deductive content analysis was conducted on the qualitative data obtained from the interviews with pre-service teachers.

\section{Participants and Ethics}

Eleven pre-service teachers participated in the study. The pre-service teachers were fourthgraders at the department of elementary school teaching in a big university (50.000 students) located in the south of Turkey. Mean age of the participants was calculated as $(\bar{X}=21.34, S D=$ .64). Moreover, seven of them $(n=7)$ were female and four of them $(n=4)$ were male. Before the selection of the participants, the pre-service teachers had been informed related to the study. A consent form which explains that volunteer pre-service teachers would be interviewed at the end of the teaching practice course, student's names and the data obtained from the interview would be hidden and also the data would not be used except for scientific research and reports. The participants were selected among the volunteers who signed the consent form.

\section{Teaching Practice Course Implementation Procedure}

A teaching practice course was implemented (nine weeks period) during the spring term in 2016. Prior to teaching practice course, a meeting was held by the supervisor (one of the authors). During the meeting, the supervisor gave information to them related to what they would do during the teaching practice. Then, pre-service teachers started teaching practice implementation. In each week, they papered lesson plans and they applied their teaching practice according to the plans. During this process, the supervisor helped them as a guide.

\section{Data Collecting Instrument}

To collect data, an instrument titled as 'Interview Form related to Learning in Teaching Practice' (IF-LTP) was used. In the IF-LTP, there were six semi-structured questions related to learning of pre-service teachers. The questions were evaluated by four experts regarding goal-oriented (content validity), quality, and clarity. At the end of the last week (the ninth week), interviews were conducted through IF-LTP and also interviews were recorded.

\section{Data Analyzing Process}

The investigators used MAXQDA 12 qualitative research software (VERBI, 2019) for the qualitative content analyses. Each interview was recorded transcribed and named as pST-1, pST2 , etc. (e.g. pre-service teacher-1 [pST-1]). The average length of each interview was approximately 35 minutes, as well as the total length of transcribed data, was 92 pages. The transcribed-files were delivered to two independent experts and the experts coded learning outcomes based on the hidden curriculum separately. After the coding process, experts discussed every code regarding the hidden curriculum, conceptual and semantic suitability. End of the discussion process final forms of codes were arranged. Finally, based on the codes given by the experts, Miles and Huberman (1994) inter-coder reliability was calculated as .86 (see Equation).

$$
\text { Reliability }=\frac{\text { Number of Agreements }}{\text { Number of Agreements }+ \text { Disagreements }}
$$

\section{RESULTS}

According to the results of the deductive content analysis, based on the "Hidden Learning Outcomes of Teaching Practice Course", totally 11 themes were determined (see Figure 1). Each of the themes had sub-themes and/or codes \& quotations (e.g. pre-service teacher-1 [pST-1]) which showed core explanations of pre-service teachers. In this section, to provide the clarity of findings, each of the themes was presented respectively. 


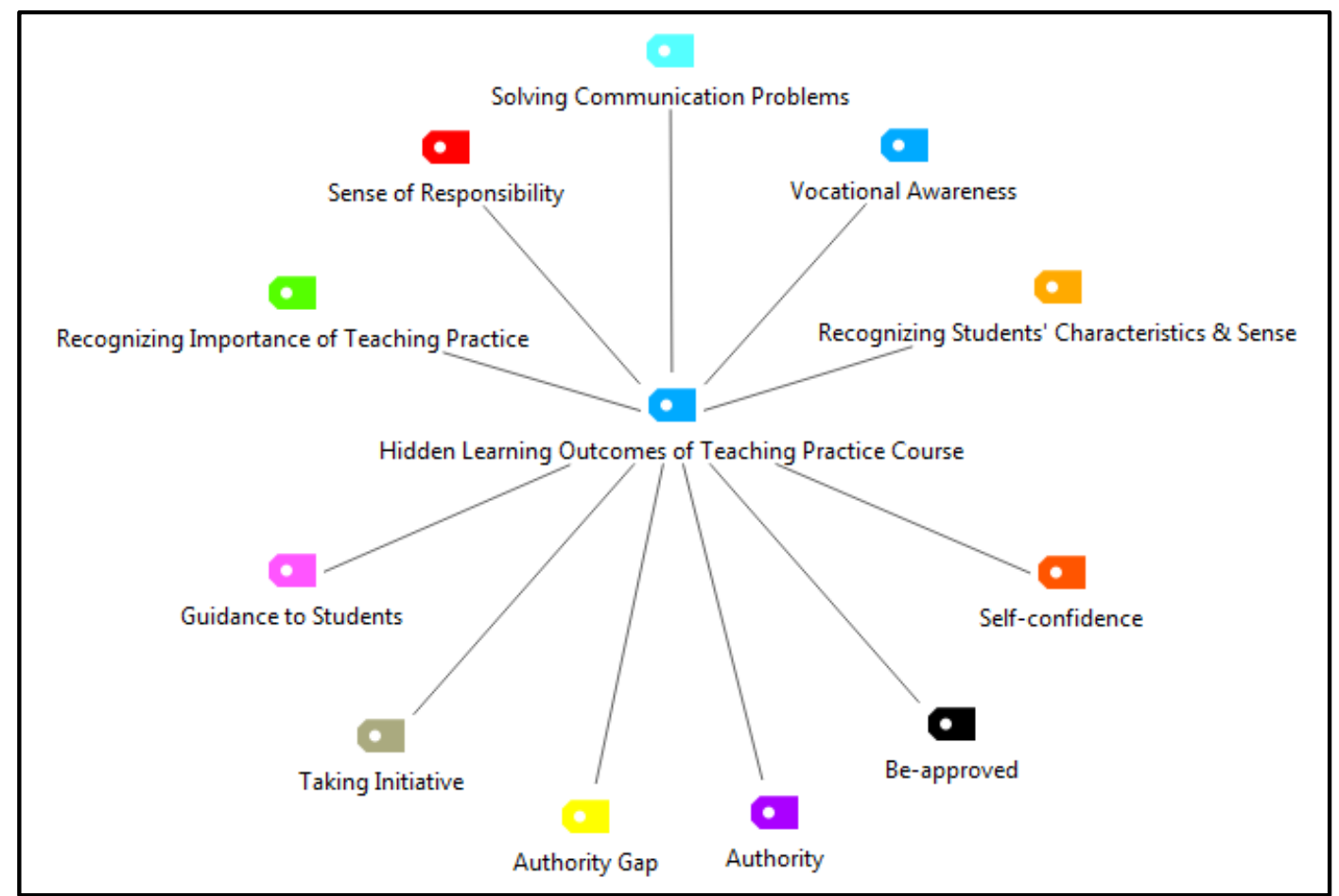

FIGURE 1. Structure of "Hidden Learning Outcomes of Teaching Practice Course".

\section{'Solving Communication Problems' Theme}

The 'Solving Communication Problems' theme shows the pre-service teachers' views of solving communication problem skills $(\mathrm{n}=3)$, which is supported by hidden curriculum activities within the classroom settings. Figure 2 shows clear explanations related to the question of how hidden curriculum activities support pre-service teachers' skills of 'Solving Communication Problems'.

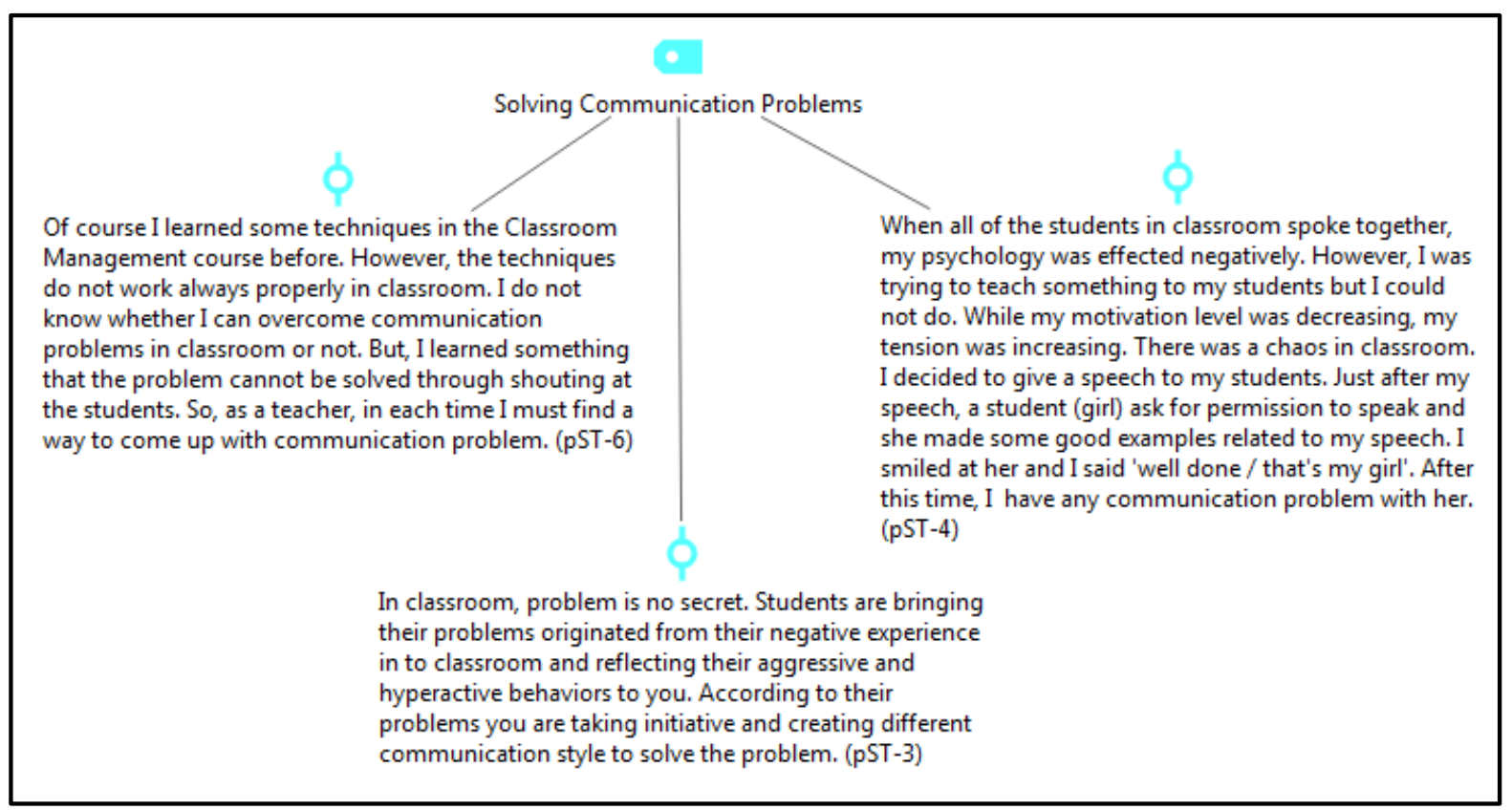

FIGURE 2. Structure of "Solving Communication Problem" theme.

\section{'Vocational Awareness' Theme}

The 'Vocational Awareness' theme has four different sub-themes titled as 'Recognizing Difficulties of Teaching Profession' stated by $(\mathrm{n}=5)$, 'Critical Thinking' stated by $(\mathrm{n}=5)$ pre-service teachers, 
'Liking Teaching Profession' stated by ( $\mathrm{n}=2)$ pre-service teachers, and 'Self-criticism' stated by $(\mathrm{n}=4)$ pre-service teachers. Moreover, to explain the characteristics of each sub-theme clearly, quotations extracted from the views of pre-service teachers are presented in Figure 3.

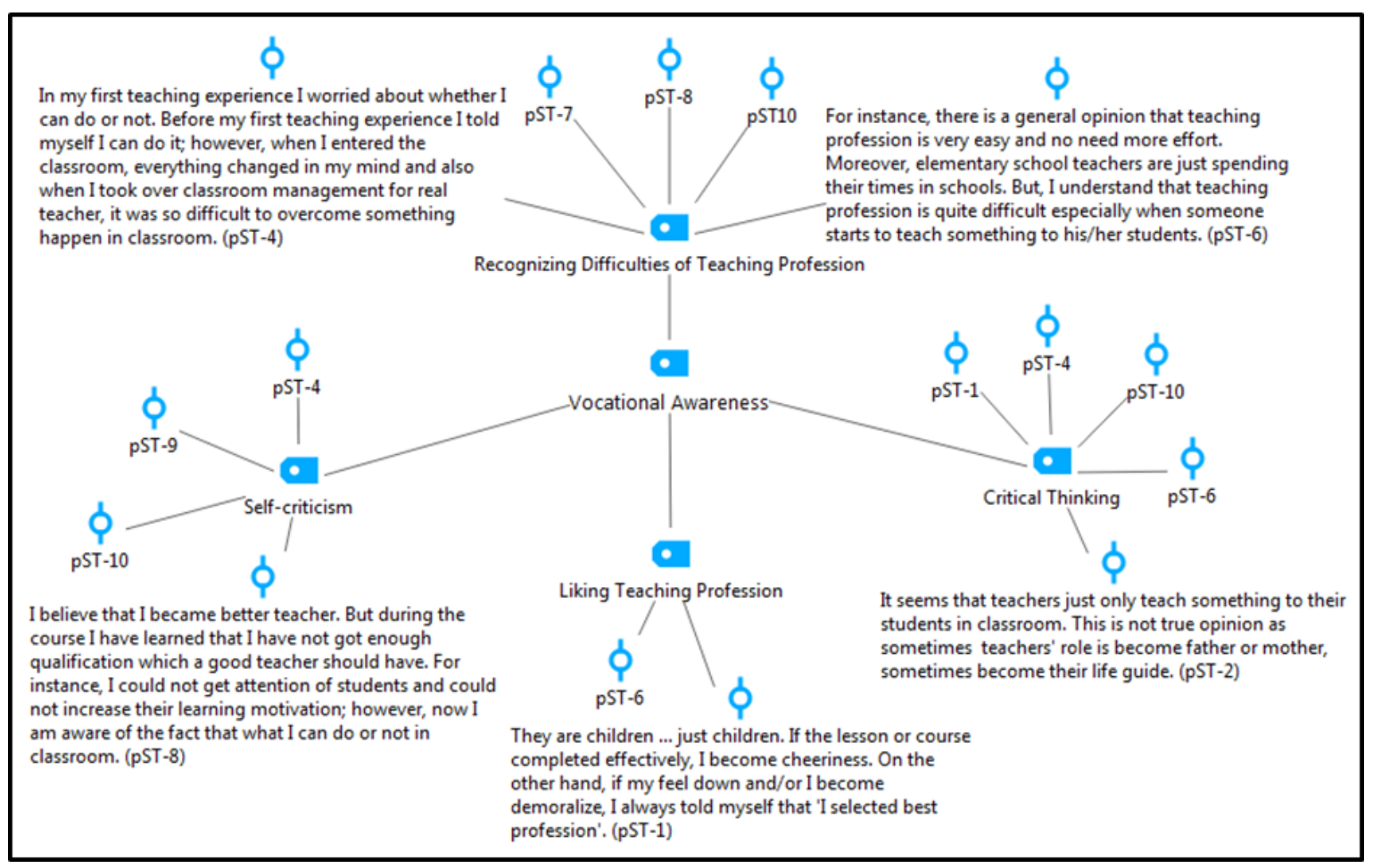

FIGURE 3. Structure of "Vocational Awareness" theme.

\section{'Recognizing Students' Characteristics \& Sense' Theme}

The 'Recognizing Students' Characteristics \& Sense' theme extracted from the views of pre-service teachers $(n=6)$ are presented in Figure 4 . While the view stated by pST-1 shows the teacher's recognition of student's characteristics, view of pST- 6 is focused on the teacher's recognition of student's sense.

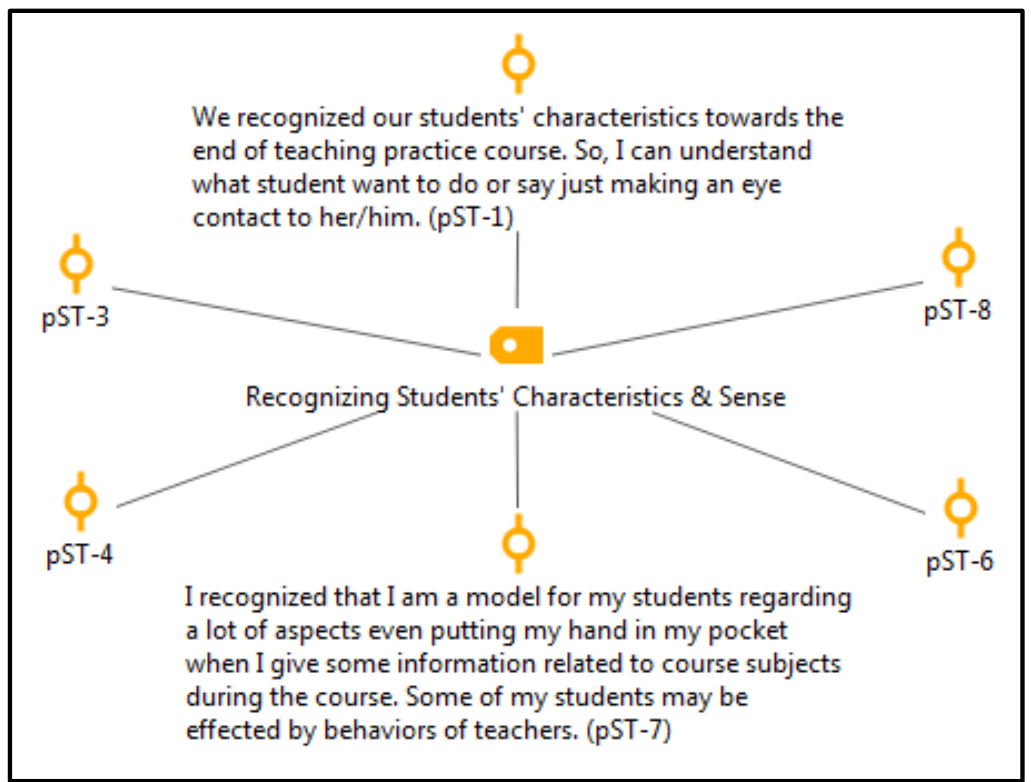

FIGURE 4. Structure of "Recognizing Students' Characteristics \& Sense" theme. 


\section{'Self Confidence' Theme}

The 'Self-confidence' theme shows one of the most important requirements which qualified teachers have. The views of pre-service teachers $(n=6)$ related to 'self-confidence' are shown in Figure 5. Based on the pre-service teachers' views, the learning in the theme is related to teacher' self-efficacy which is one of the most important goals of the OTTC. In this context, it can be said that this implicit learning can act as a catalyst that stimulates pre-service teachers' self-efficacy.

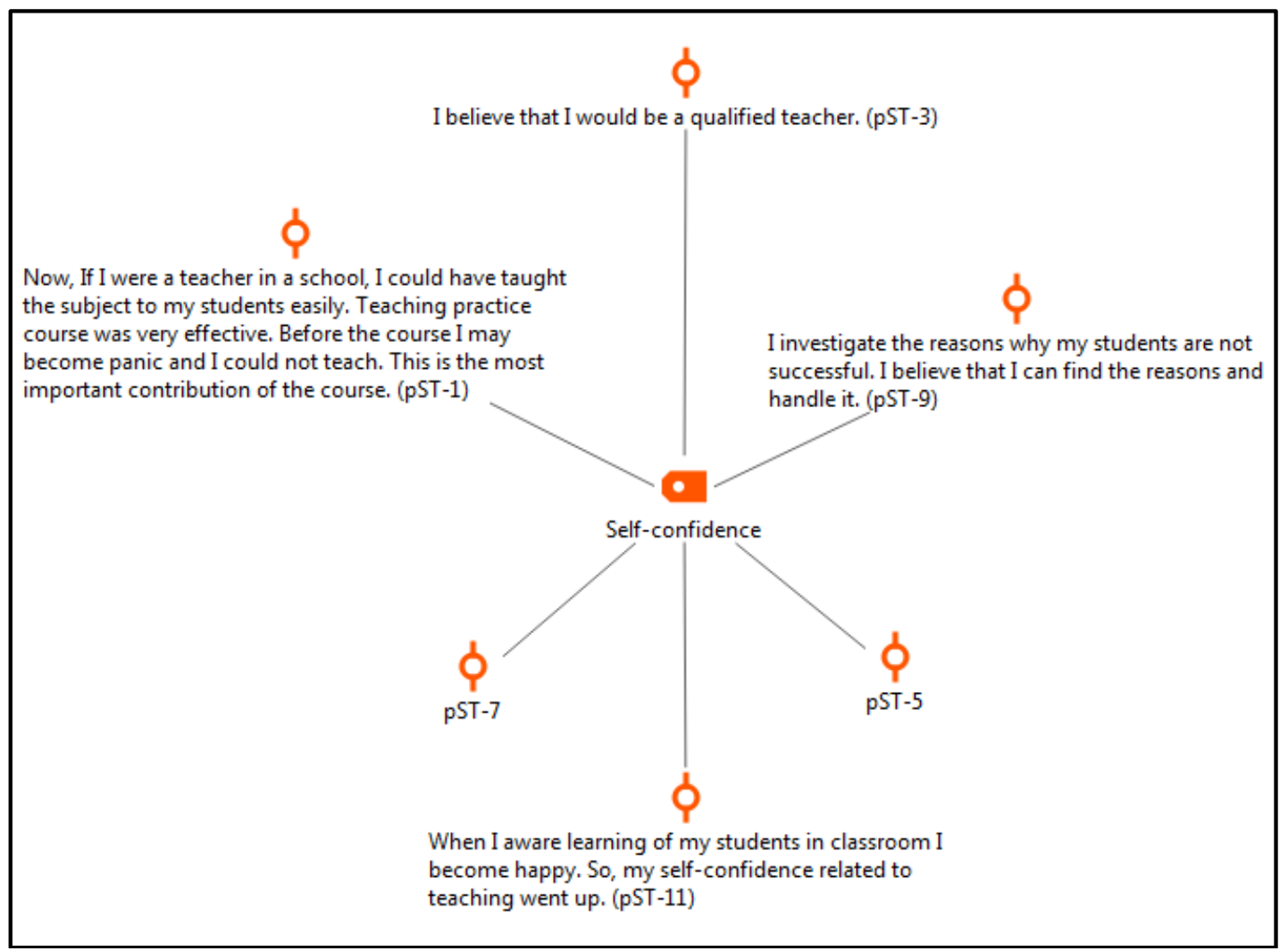

FIGURE 5. Structure of "Self-confidence" theme.

\section{'Be Approved' Theme}

The 'Be-approved' theme shows one of the most important needs for teachers' effective classroom experience regarding both classroom management and teaching. Views of pre-service teachers $(n=3)$ related to the theme and two quotations extracted from the views are shown in Figure 6.

\section{$\phi$}

For instance, I promised to bring something into the classroom to my students. But, due to my problem (one of my relatives' funeral ceremony) I could not do my promise. Next week, my students told me that they missed me and also they remind me the promise which I had gave them. I felt something between me and students! Yes, there is a relationship among us and I understand that they accepted me as a teacher. (pST-9)

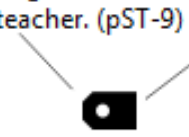

Be-approved

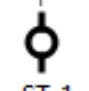

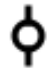

In fact, when I entered in to classroom, students become happy, in that, at the last week of teaching practice, they told me please do not go... (pST-11)

\footnotetext{
FIGURE 6. Structure of "Be-approved" theme.
} 


\section{'Authority' Theme}

The 'Authority' theme shows authoritarian leadership need of a teacher in order to manage students' behaviors and arrange classroom settings. In this context, views of pre-service teachers $(n=5)$ related to the theme and four quotations extracted from the views are shown in Figure 7.

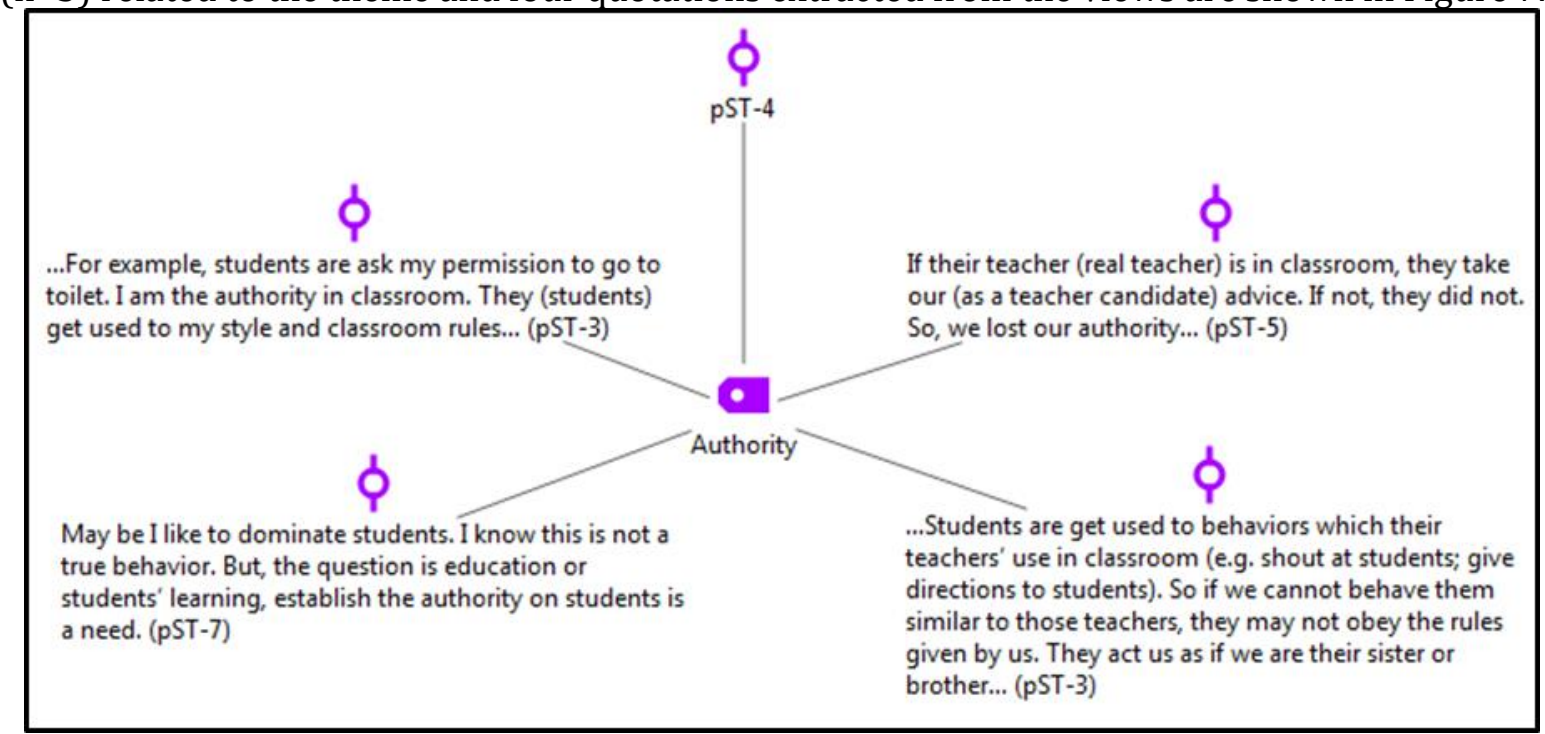

\section{'Authority Gap' Theme}

FIGURE 7. Structure of "Authority" theme.

The 'Authority Gap' theme shows a gap related to come down of the teacher's leadership characteristic. In other words, it can be defined as cutting down the teacher's in-class authority. Moreover, the theme and the quotations of pre-service teachers $(n=2)$ are shown in Figure 8. 
...Due to bevy classroom, I slogged up in-class activities. When I prepared (it was really hard) my classroom settings and my students for learning activities, real teachers of this class get into the classroom (He is one of the school managers) so that concentration of my students and me decreased dramatically... Oh my god! May be three or four times I experienced same problem. I could not do anything and in fact I was not a teacher in that courses... (pST-3)

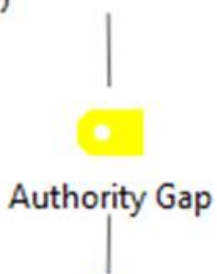

...After two or three weeks, we are very close with our students. For this reason, they may not focus on our courses as they are very close with us! There is no problem for them! According to them we are not seem as a teacher... Moreover, they know the fact that we are trainee teacher in their classroom. So we have some difficulties... (pST-8)

FIGURE 8. Structure of "Authority Gap" theme.

\section{'Taking Initiative' Theme}

The 'Taking Initiative' theme shows one of the requirements which teachers may be obliged to use during in-class applications according to the psychological atmosphere of the classroom. Moreover, the structure of the theme and the quotations of pre-service teachers $(n=2)$ are shown in Figure 9.

For example, students are ask my permission to go to toilet. I do not know whether students tell me the truth or not. May be he/she want to disrupt the lesson. So, I must take initiative... According to my prediction sometimes I give permission but sometimes not... (pST-1)

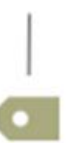

Taking Initiative

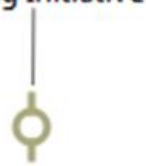

Classroom management is not similar to knowledge which we read from books and learned from our teachers. Get a checklist and put some ticks... No, real one is not easy... There is a different atmosphere in classroom and frequently I had to take initiatives different from our previous learning... (pST-4)

FIGURE 9. Structure of "Taking Initiative" theme. 


\section{'Guidance to Students' Theme}

The 'Guidance to Students' theme shows one of the affective and hidden learning outcomes which is a highly important awareness for a qualified teacher. Moreover, the structure of the theme and the quotations of pre-service teachers ( $\mathrm{n}=5)$ are shown in Figure 10.

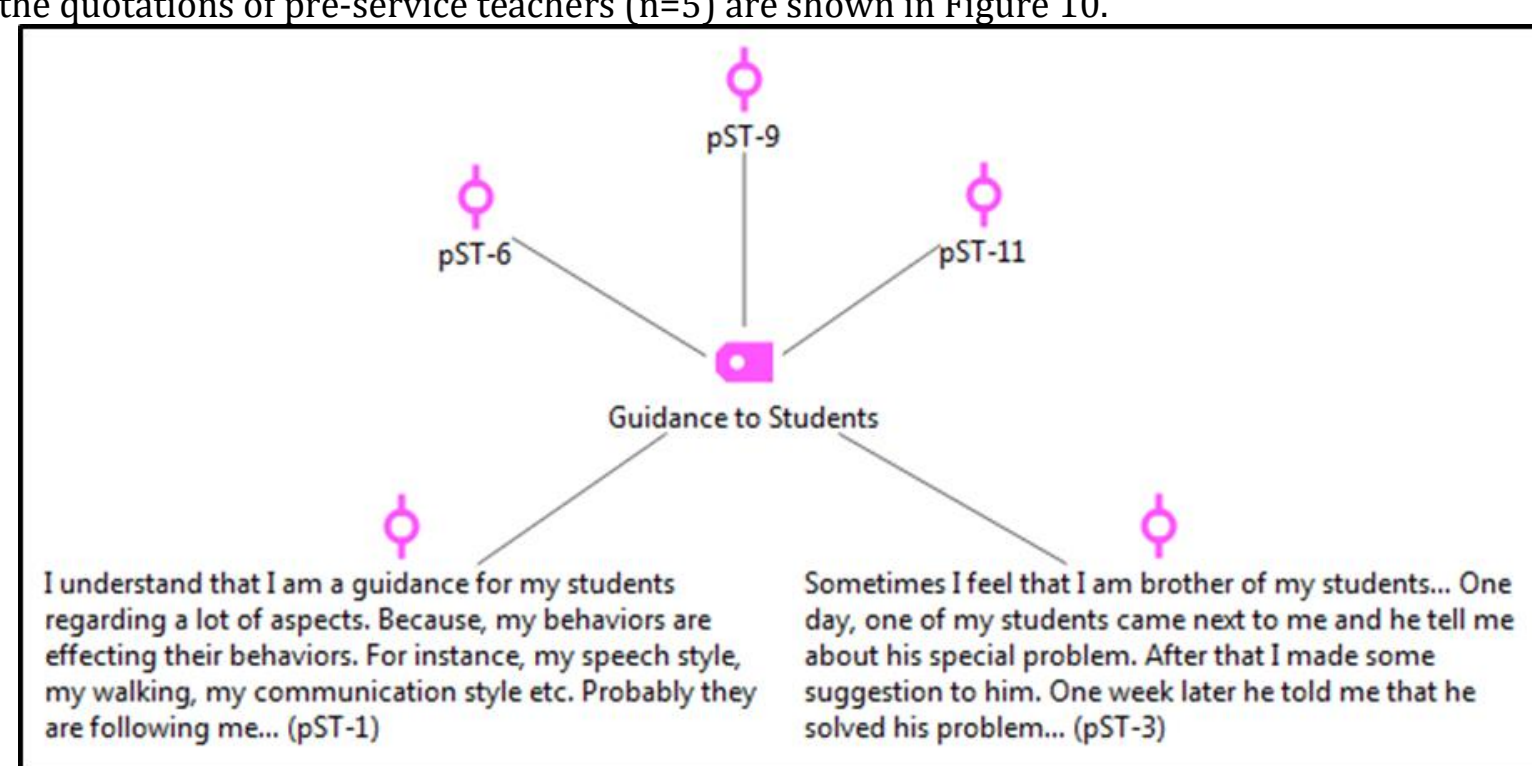

FIGURE 10. Structure of "Guidance to Students" theme.

\section{'Recognizing Importance of Teaching Practice' Theme}

The 'Recognizing Importance of Teaching Practice' theme shows one of the important affective hidden learning outcomes related to pre-service teachers' prior teaching practice experiences. In that, within the theme, there is a code named as 'Lack of Guidance' extracted from the views of pre-service teachers $(n=3)$. Moreover, the theme includes totally $(n=8 / 11)$ views of pre-service teachers. The basic structure of the theme, and the lack of guidance code as well as the quotations of $(n=2)$ pre-service teachers are shown in Figure 11.

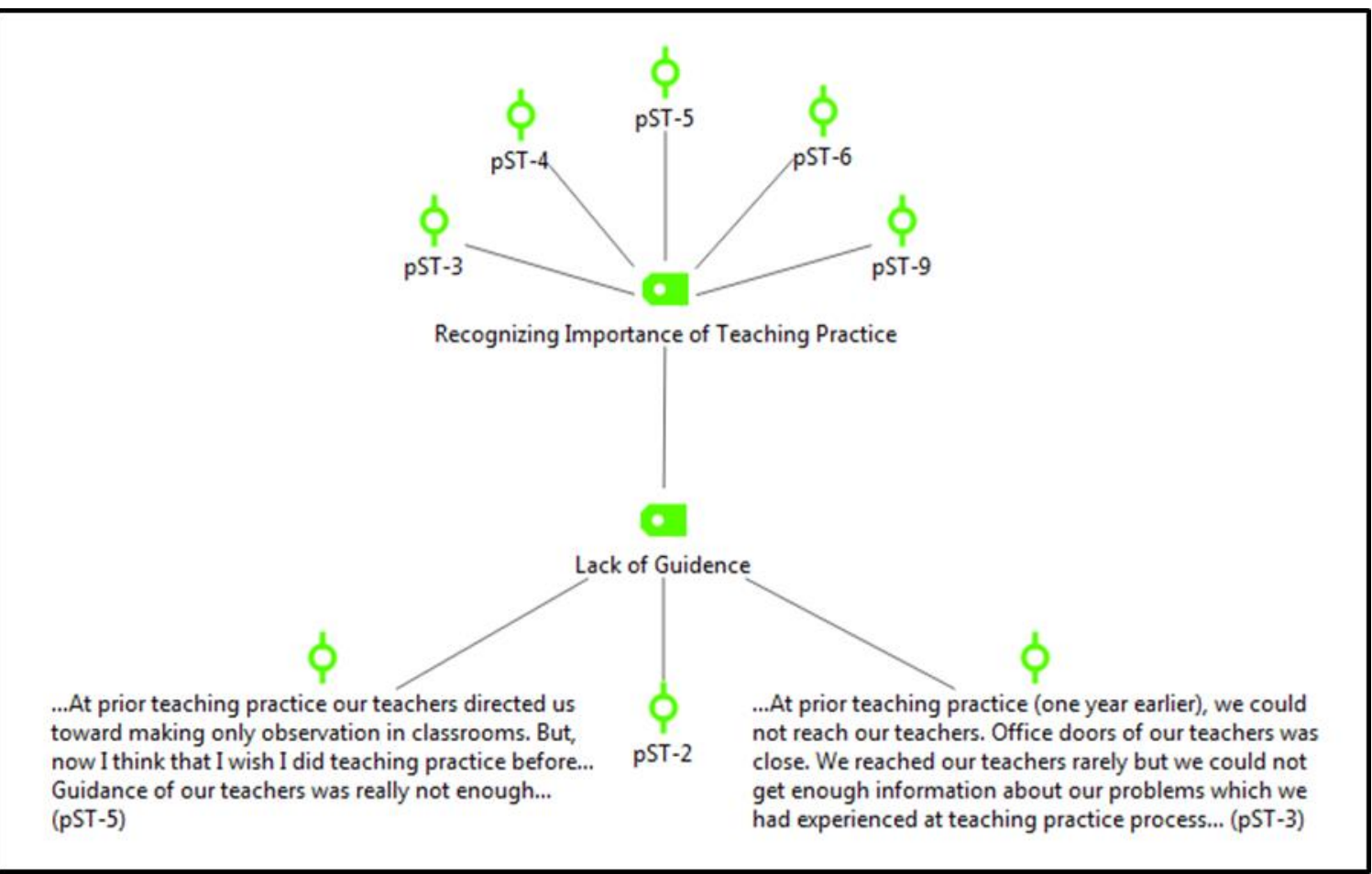

FIGURE 11. Structure of "Recognizing Importance of Teaching Practice" theme. 


\section{'Sense of Responsibility' Theme}

The 'Sense of Responsibility' theme shows the teacher's one of the needs when he/she works in a classroom. In that, during the teaching practice process, there is a likelihood that there will be a relationship among pre-service teachers (as a teacher) and students related to students' needs, teachers' expectations, etc. So, pre-service teachers as a leader may have a sense of responsibility for their students. The theme includes totally views of $(n=5)$ pre-service teachers. The basic structure of the theme and the quotations of pre-service teachers $(\mathrm{n}=2)$ are shown in Figure 12.

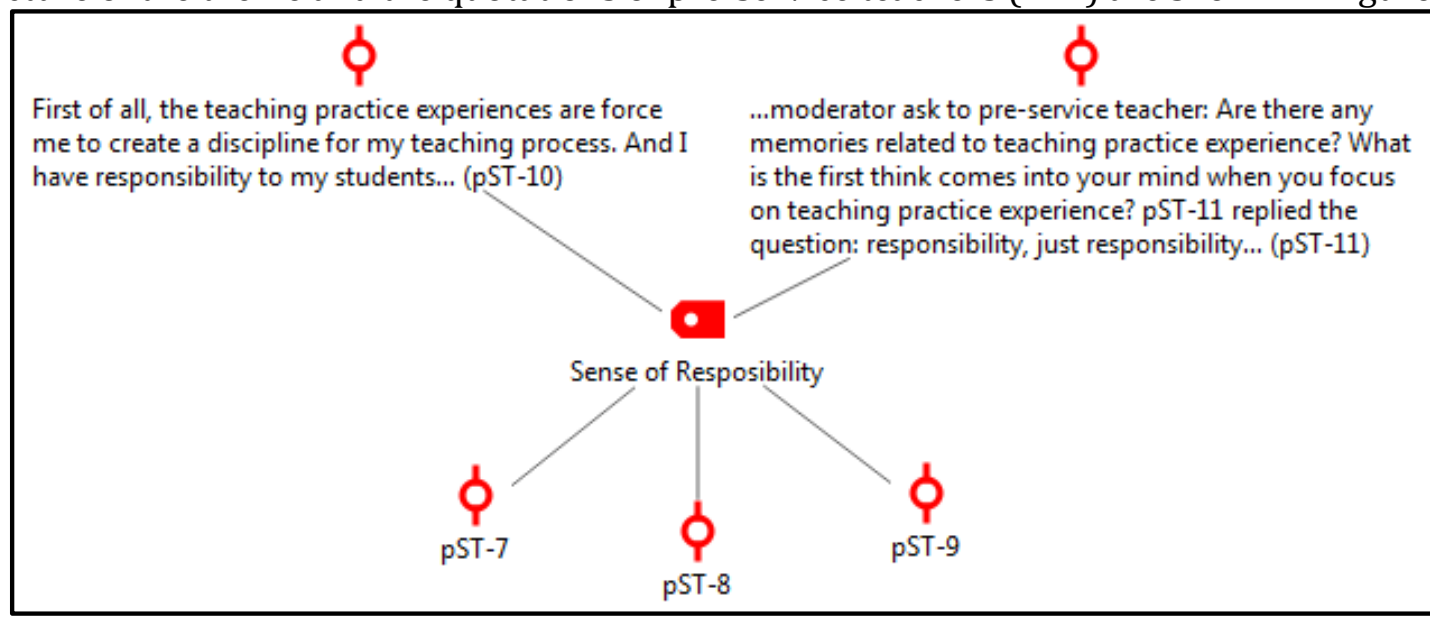

FIGURE 12. Structure of "Sense of Responsibility" theme.

\section{DISCUSSION and CONCLUSIONS}

Results of the analysis show that the learning outcomes obtained from the interviews indicate that the pre-service teachers' learning, within the HC, appeared under 11 different themes (see Figure 1). The results have been discussed based on the hidden curriculum, preservice teachers' professional development process, the teaching profession, metacognition, and the official teacher training curriculum perspectives.

When we focus on the figure out the message of the 11 themes (see Figure 1); even though the themes have complex structure on their own, they explicitly show that hidden learning outcomes reflect three basic learning domains as "learning to learn" (LL), "learning the profession" (LP) and "learning to be expert" (LBE). The same domains were stated by Ahola's (2000) study. The themes also give similar signs with the description of Sambell and McDowel (1998) which focuses on learners' ill-defined implicit educational experiences apart from the formal curriculum. Furthermore, within HC, learning outcomes of pre-service directly relate to the students' personality behaviors (Condon et al. 2014; Zorec \& Dosler, 2016), rules and structures of school and classroom (Dutton et al. 2001; Winter \& Cotton, 2012), classroom climate (Dutton, 1987) and students' hidden messages (Lynch, 1989; Sarl, 2007). Therefore, general structure of the learning themes is compatible with the HC literature as well.

On the other hand, in relation to learning domains as stated above the themes should be divided into three categories as LL, LP, and LBE. In this classification process, the codes and the direct quotations of the pre-service teachers are taken into consideration. In this regard, the classification emerged from the themes are shown in Table 1.

Table 1. Domains of pre-service teachers' learning outcomes within HC.

\begin{tabular}{lll}
\hline LL & LP & LBE \\
\hline Taking Initiative & Solving communication problems & Recognizing Importance of Teaching \\
& Vocational Awareness & Practice \\
& Sense of Responsibility & Guidance to Students \\
& Self-Confidence & \\
\hline
\end{tabular}


Be-Approved

Authority

Authority Gap
Recognizing Students' Characteristics

and Sense

It can be described that the pre-service teachers' learning outcomes are mostly within the scope of LP and LBE domains but only one is in the scope of LL. They also give an explanation regarding Langhout and Mitchell's (2008) question stated as how hidden curriculum supports the teacher's creation of academically engaging learning environment for students (p. 594). Therefore, it can be asserted that the learning of pre-service teachers within the teaching practice course, supports their professional development and also the learning is vital for their profession. Maulana et al., (2015) state that in the earlier stage of the profession, teachers encounter some difficulties such as preparing supportive learning climate, providing effective classroom management, supporting the students according to individual differences and needs. In this regard, especially the themes "Solving Communication Problems", "Recognizing Students' Characteristics and Sense", "Be-Approved" and "Authority Gap" reflect the difficulties which preservice teachers experienced. Furthermore, these problems clearly evident that if the pre-service teachers participate the teaching practice in a long term, potential difficulties which the teachers may encounter within their earlier stage of the profession can be blocked. Therefore, the preservice teachers' learning within $\mathrm{HC}$ work as a prevention of earlier stage teaching profession difficulties curriculum.

Within the scope of the learning in the LP and the LBE domain, "Be-Approved" and "Authority Gap" learning themes, can be supported by current OTTC if some arrangements are made. In that, if the students in a classroom perceive a message that the pre-service teacher in their classroom is a secondary teacher and his/her stimulus, cues, directions, etc. are not important, the pre-service teachers may easily loss of the control within the classroom. Although this negative classroom climate originated from the unsuitable behaviours of primary classroom teacher and/or administrators impairs the pre-service teachers' professional development process, it can be accomplished by certificating the primary classroom teachers, administrators, and the schools. Both three variables (primary classroom teachers, administrators, and schools) should be specifically selected and designed for teaching practice course and pre-service teachers. In addition, it is clear that the pre-service teachers need to use metacognitive thinking skills to reach the learning within the HC. In that, the term metacognition simply refers to someone's knowledge, awareness of their own cognitive processes and anything related to them (Flavell, 1976). The metacognitive skills incorporate in some skills such as self-awareness, selfevaluate, self-reflection (Kuiper \& Pesut, 2004) and it also has three components as metacognitive knowledge, metacognitive regulation and metacognitive experiences (Louca, 2019). Moreover, metacognitive experiences are those experiences that have something to do with the awareness of current, on-going cognitive endeavour (Louca, 2019, p.56). In this regard, the pre-service teachers have a series of experience stem from the teaching practice and they get the implicit messages if they cognitively have enough self-awareness. Also, if they have enough metacognitive experience skill within their OTTC, they can create a suitable way to exceed the problem situation which they encountered in the classroom. The explanation of the problem stated "Why preservice teachers' metacognitive skills must be developed before the teaching practice?" is that the pre-service teachers probably have the first experience in that type of situation since the situation stems from the ill-defined implicit educational experiences apart from the formal curriculum (Sambell \& McDowel, 1998).

Finally, the findings are suitable with one of the two theories lies under HC called micro (social constructivist) approach. While the macro (Marxist sociology) approach raised by Bowles and Gintis (1976) states that the ruling class (bourgeoisie) are able to manipulate the working class (proletariats) through the HC, micro approach ignores the official program, and the school is seen as an organization where the actors (teachers and services) have interactions. Based on this view, it can be stated that pre-service teachers' hidden learning outcomes are arise from the interactions among pre-service teacher, students and school administrators. Pre-service 
teachers' adviser in the university has fewer role than the others. Nevertheless, apart from the people (teacher candidates, students, and school administrators) affecting hidden learnings of pre-service teachers, the functioning - structure - facilities and rules of the school that shape those people are also important factors enable the HC.

\section{REFERENCES}

Anderson, T. (2001). The Hidden Curriculum in Distance Education An Updated View. Change: The Magazine of Higher Learning, 33(6), 28-35, https://www.doi.org/10.1080/00091380109601824

Bergenhenegouwen, G. (1987). Hidden Curriculum in the University. Higher Education, 16(5), 535-543.

Biermann, A., Karbach, J., Spinath, F. M., \& Brunken, R. (2015). Investigating effects of the quality of field experiences and personality on perceived teaching skills in German pre-service teachers for secondary schools. Teaching and Teacher Education, 51, 77-87, https://www.doi.org/10.1016/j.tate.2015.06.005

Bowles, S., \& Gintis, H. (1976). Schooling in Capitalist America: Educational Reform and the Contradictions of Economic Life. New York: Basic Books

Cabaroglu, N., \& Roberts, J. (2000). Development in student teachers' pre-existing beliefs during a 1-year PGCE programme. System, 28(3), 387-402.

Condon, B. B., Grimsley, C., Kelley, T., \& Nissen, M. K. (2014). End of Life and Beyond as Hidden Curriculum. Nursing Science Quarterly, 27(1) 23 - 28, https://www.doi.org/10.1177/0894318413509690

Darling-Hammond, L., \& Post, L. (2000). Inequality in teaching and schooling: supporting high-quality teaching and leadership in low-income schools. In Kahlenberg, R. D. (Eds.), A nation at risk: Preserving public education as an engine for social mobility (pp. 127-167). New York: Century Foundation Press.

Dutton, T. A. (1987). Design and studio pedagogy. Journal of Architectural Education 41(1), 16-25.

Fan Tang, S. Y. (2004). The dynamics of school-based learning in initial teacher education. Research Papers in Education, 19(2), 185-204.

Feagin, J. R., Orum, A. M. \& Sjoberg, G. (Eds.). (1991). A Case for the Case Study. University of North Carolina Press, Chapel Hill, NC.

Flyvbjerg, B. (2006). Five Misunderstandings About Case-Study Research. Qualitative Inquiry, 12(2), 219245.

Flavell, J. H. (1976). Metacognitive aspects of problem solving. In L. B. Resnick (Ed.). The nature of intelligence (pp. 231-236). Hillsdale, NJ: Erlbaum.

Gattett, J. L. (2010). Hidden Messages in the Curriculum. Kappa Delta Pi Record, 46(2), 58-59, https://www.doi.org/10.1080/00228958.2010.10516694

Gebhard, J. (2009). The practicum. In A. Burns, \& J. C. Richards (Eds.), The Cambridge guide to second language teacher education (pp. 250-258). New York: Cambridge University Press

Hafferty, F. W. \& O'Donnell, J. F. (2014). The hidden curriculum in health professional education. Lebanon: University Press of New England.

Horn Jr, R. A. (2003). Developing a critical awareness of the hidden curriculum through media literacy. The Clearing House, 76(6), 298-300.

Jackson, P. W. (1968). Life in Classrooms. New York: Teachers College Press.

Kagan, D. M. (1992). Implication of research on teacher belief. Educational Psychologist, 27(1), 65-90.

Konieczka, J. (2013). The hidden curriculum. Proceedings in ARSA-Advanced Research in Scientific Areas, 1, 250-252.

Kuiper, R. \& Pesut D. J. (2004). Promoting cognitive and metacognitive reflective reasoning skills in nursing practice: Self-regulated learning theory. Journal of Advanced Nursing 45(4), 381-91. https://www.doi.org/10.1046/j.1365-2648.2003.02921.x

Langhout, R. D., \& Mitchell, C. A. (2008). Engaging Contexts: Drawing the Link between Student and Teacher Experiences of the Hidden Curriculum. Journal of Community \& Applied Social Psychology, 18(6), 593-614, https://www.doi.org/10.1002/casp.974

Louca, E. P. (2019). Do children know what they know? Metacognitive awareness in preschool children. New Ideas in Psychology, 54, 56-62.

Lynch, K. (1989). The Hidden Curriculum: reproduction in education, a reappraisal. London: Falmer Press. Margolis, E., Soldatenko, M., Acker, S., \& Gair, M. (2001). Hiding and Outing the Curriculum. In E. Margolis (Eds.), The Hidden Curriculum in Higher Education (pp. 1-20). New York: Routledge. 
Maulana, R., Opdenakker, M.-C., Stroet, K., \& Bosker, R. (2013). Changes in teachers' involvement versus rejection and links with academic motivation during the first year of secondary education: a multilevel growth curve analysis. Journal of Youth and Adolescence, 42(9), 1348-1371, https://www.doi.org/10.1007/s10964-013-9921-9

Maulana, R., Helms-Lorenz, M., \& van de Grift, W. (2015). A longitudinal study of induction on the acceleration of growth in teaching quality of beginning teachers through the eyes of their students. Teaching and Teacher Education, 51, 225-245, https://www.doi.org/10.1016/j.tate.2015.07.003

Murphy, P. K., Delli, L. A. M., \& Edwards, M. N. (2004). The good teacher and good teaching: Comparing beliefs of second-grade students, preservice teachers, and inservice teachers. Journal of Experimental Education, 72(2), 69-92, https://www.doi.org/10.3200/Jexe.72.2.69-92

Ng, W., Nicholas, H., \& Williams, A. (2010). School experience influences on pre-service teachers' evolving beliefs about effective teaching. Teaching and Teacher Education, 26(2), 278-289, https://www.doi.org/10.1016/j.tate.2009.03.010

Peske, H. G., and Haycock, K. (2006). Teaching Inequality: How Poor and Minority Students Are Shortchanged on Teacher Quality: A Report and Recommendations by the Education Trust. Education Trust.

Sambell, K. \& McDowell, L. (1998). The Construction of the Hidden Curriculum: messages and meanings in the assessment of student learning. Assessment \& Evaluation in Higher Education, 23(4), 391-402, https://www.doi.org/10.1080/0260293980230406

Sarı, M. (2007). The effect of hidden curriculum on gaining democratic values: A qualitative study in two elementary schools having low and high quality of school life (Unpublished Ph.D. Thesis). Çukurova University Social Sciences Institute, Adana.

Senemoğlu, N. (1993). A study on initial primary teacher training in England with implications for the system in Turkey. Hacettepe Üniversitesi Eğitim Fakültesi Dergisi, 9(9), 367-376.

Skelton, A. (1997). Studying hidden curricula: developing a perspective in the light of postmodern insights. Curriculum Studies, 5(2), 177-193, https://www.doi.org/10.1080/14681369700200007

Tang, E. L., Lee, J. C., \& Chun, C. K. (2012). Development of teaching beliefs and the focus of change in the process of pre-service ESL teacher education. Australian Journal of Teacher Education, 37(5), 90107, https://www.doi.org/10.14221/ajte.2012v37n5.8

Winter, J., \& Cotton, D. (2012). Making the hidden curriculum visible: sustainability literacy in higher education. Environmental Education Research, 18(6), 783-796, https://www.doi.org/10.1080/13504622.2012.670207

Yuan, R., \& Lee, I. (2014). Pre-service teachers' changing beliefs in the teaching practicum: Three cases in an EFL context. System, 44, 1-12, https://www.doi.org/10.1016/j.system.2014.02.002

Zorec, M. B., \& Došler, A. J. (2016) Rethinking the hidden curriculum: daily routine in Slovene preschools. European Early Childhood Education Research Journal, 24(1), 103-114, https://www.doi.org/10.1080/1350293X.2015.1120523 


\section{Appendix}

Table A. Objectives of teaching practice course (for Elementary School - Classroom Teacher). Objectives

- Teacher candidate can establish clear communication with her/his students.

- Teacher candidate can determine students' needs before the instruction.

- Based on course objectives, teacher candidate can prepare an instructional lesson plan suitable for effective teaching and student activity.

- Based on course objectives, teacher candidate can select instructional materials and tools.

- Teacher candidate can develop an instructional material when she/he needs.

- Teacher candidate can use voice tone and body language effectively during the instruction process.

- According to instructional plan, teacher candidate can arrange students' seating structure in the classroom.

- Teacher candidate can use technological tools (computer, tablet, internet etc.) effectively in accordance with instructional plan.

- Teacher candidate can apply the instructional plan effectively.

- Teacher candidate can give suitable feedback to her/his students' explanations and tasks (homework, project, activities etc.)

- Teacher candidate can lead and guide her/his students in the instructional process.

- Teacher candidate can ask questions which contribute learning to her/his students during the course.

- Teacher candidate can use suitable reinforcements within the instructional process.

- Teacher candidate can evaluate the instruction by using suitable techniques.

- Teacher candidate can prepare and apply proper measurement tools to assess her/his students. 